\title{
Features of Subjective Control Localization for the High-Class Athletes
}

\author{
Popova M. V. \\ Churapchinsky State Institute of Physical Culture and Sports \\ Churapcha, Russia \\ pmvchurapcha@yandex.ru
}

\author{
Makarova T. A. \\ Churapchinsky State Institute of Physical Culture and Sports \\ Churapcha, Russia \\ makarova-tatina@mail.ru
}

\author{
Manasytova M. A. \\ Churapchinsky State Institute of Physical Culture and Sports» \\ Churapcha, Russia \\ manasytovam@mail.ru
}

\begin{abstract}
The article presents the results of a control locus comparative analysis in students-athletes of physical education University, having sports titles and categories "Master of sports of Russia", "Candidate for master of sports", from the first to the third sports category, not having a sports category and not involved in sports. It is shown that these categories of groups have their own characteristics in the degree of responsibility for their actions and behavior in such spheres and events of life as: in the field of achievements, family, industrial and interpersonal relations, in the field of health and disease. And reliably all differ in the ability to successfully achieve the tasks set, to go to the intended target in the future.
\end{abstract}

Keywords - students; athletes of different sports qualifications; locus of control.

\section{INTRODUCTION}

At the present stage of the society development, with its social instability and new realities, the requirements for a person who wants to achieve certain results in his life have increased. From this point of view, actual for psychological science becomes the problem of means search and methods searching to enhance self-control assisting the person to manage himself, own behavior under adverse conditions.

\section{LITERATURE REVIEW}

In the scientific world, self-control is presented as a necessary component of the self-government and selfregulation process, development of consciousness and selfconsciousness of a person (K. A. Abulkhanova-Slavskaya, B. A. Bodrov, E. P. Ilyin, O. A. Konopkin, JI.B. Kulikov, G. S. Nikiforov, C. JI. Rubinstein.) Self-control is considered mainly in two aspects. As a process [3; 13] and as the quality of personality (S. L. Rubinstein, R. Kettell).

In this direction, we are interested in the aspect of selfcontrol as a characteristic of personality. The formulation of this question is widely presented In the work of O. N. Nikolaenko [12]. The author emphasizes this feature as a quality of personality, formed during human life, associated with self-control, perseverance and other qualities related to the will. And also emphasizes the role of socialization in the development of this quality.

One of the brightest of these conditions, acts and sports activities. And as Lubysheva L.I. notes [10] sport today, particularly is needed because of the modern times makes the person the most important condition to be competitive.

\section{RESEARCH METHODOLOGY}

The purpose of the study was to reveal the peculiarities of subjective control localization in athletes of high class.

With the purpose of control localization features revealing over significant events in skilled athletes, we studied and conducted a comparative analysis of these indicators in athletes of different sports qualifications and sports categories. As well as athletes with sports categories and do not involved in sports. Using The questionnaire of subjective control by Julian Rotter was used [8].

The technique is a modified version of the American psychologist J.P. Rotter questionnaire. It assess the degree of human responsibility in the field of achievements, family, industrial and interpersonal relations, in the field of health and disease. In two polar localizations: external (when a person believes that what is happening with him does not depend on it, it is the result of external causes) and internal (in this case, a person explains his significant events in life as the result of his own efforts).

The basis is held at the Churapchinsky state Institute of physical culture and sports of the Churapchinsky ulus of the Republic of Sakha (Yakutia). 4 samples were formed in the amount of 252 people. The first sample included 77 athletes with the sports title "Master of sports" (MS) and candidates for master of sports (CMS). The second sample consisted of 65 student-athletes with mass sports categories. The third group consisted of 65 student-athletes who do not have sports 
qualifications. In the fourth were 45 students not involved in sports.

\section{RESULTS}

Each sample has its own polar types of localization of control over significant situations and spheres of life. Athletes MS and CMS revealed higher rates of internality in the field of achievements, which suggests that their ability to successfully pursue their goals in the future, and does not attribute their successes, achievements luck, external circumstances.

Athletes mass sports categories characterized by a lower level of self-control in interpersonal relationships. This indicates that the subject is not inclined to take responsibility for their relationships with others. And lower indicators, compared with other samples, on the level of responsibility in the field of family relations, manifested in the ability to see the cause of significant situations in the family of their partners, not themselves.

Athletes that do not have sports qualifications in comparison with other samples internality in the field of failures is not accented. The tendency to blame himself in various troubles and failures is noticed in all samples.

In turn, students not involved in sports have lower indicators of subjective control in relation to health and disease. This suggests that they believe their health is the result of external circumstances, events, and recovery will come as a result of the other people, actions and especially doctors.

Further, we, using the "student's t-test", conducted a comparative analysis of significant differences between indices of the responsibility degree for their actions and behavior in students of CHGIFKIS having sports qualification MS, CMS, mass discharges, without sports qualifications and not involved in sports.

\section{DISCUSSION}

Based on the results of the study and statistical analysis of the results, we can state the assumption that sports activities, entirely aimed at achieving the best sports results, and taking place in extreme conditions for humans $[2 ; 6 ; 11 ; 15 ; 1]$ it creates conditions for the formation of individual personality properties that allow to work and to function effectively on the ultimate capabilities of human resources.

In this perspective, there is a question about the means and methods of the physical education process reorientation in athletic training that will create conditions for the formation of the students' competitive personality. Moreover, this process will allow for the implementation of the national sports as the basis of spirituality and morality of the younger generation ecological culture, as the foundation of stress resistance in achieving the goals in life $[16 ; 14 ; 7 ; 5 ; 4 ; 9]$.

\section{CONCLUSIONS}

Overall, the results of the subjective control severity comparative analysis in 4 samples that allow us to state the following typical athletic high-class features of subjective control at TCR $(\mathrm{p}<0.05)$ 1.97:

- authentically high indicators of responsibility in the field of achievements in comparison with athletes of mass sports categories $(3,4)$, with athletes who do not have sports qualifications (2) and students who are not engaged in sports $(2,5)$;

- reliably high indicators of responsibility in the field of family relations in comparison with athletes of mass sports categories $(3,4)$, and students who are not engaged in sports $(2,2)$;

- reliably high indicators of responsibility in the field of industrial relations with students not involved in sports $(2,2)$;

- authentically high indicators of responsibility in the field of interpersonal relations in comparison with athletes of mass sports categories $(2,7)$;

- significantly high levels of responsibility in the field of interpersonal relations in comparison with students who do not play sports $(2,2)$.

\section{References}

[1] Adamovich G.E. Psychomotor reliability of students under the influence of extreme loads. Extreme human activity: materials of scientific and practical conference. M. 2008, pp. 140-151.

[2] Alekseev A.V. Above and beyond. Moscow: physical culture and sport. 2003, 280.

[3] Vladimirov I.Yu. Controlling control and intuition at various stages of creative decision. Psychological Journal. 2016, vol. 37, 1, pp. 48 - 60 .

[4] Gulyaeva S.S. Studying the opinion of experts on the effectiveness of national sports and their popularity among the population. Topical issues of development and scientific methodological support of national sports and folk games of the republic of Sakha (Yakutia): materials of the all-Russian scientific conference with international participation. Yakutsk. 2017, pp. 80-81.

[5] Gulyaeva A.N. National folk games and exercises as an effective means of educating young athletes. Topical issues of development and scientific methodological support of national sports and folk games of the republic of Sakha (Yakutia): materials of the all-Russian scientific conference with international participation. Yakutsk. 2017, pp. 77-79.

[6] Zagainov R.M. Crisis situations in sport and the psychology of overcoming them: a monograph. Soviet sport. 2010, 232.

[7] Kochnev V.P. Historical aspects of the development of national sports, as part of the spiritual development of the sakha people. Topical issues of development and scientific methodological support of national sports and folk games of the republic of Sakha (Yakutia): materials of the allRussian scientific conference with international participation. Yakutsk. 2017, pp. 167-171.

[8] Ksenofontova E.G. Study of the lokus of control: new version of "level of subjective control". Psychological journal. 1999, vol. 20, 2, pp. 103114.

[9] Kucesheva I.L. On the development of national sports and folk games. Actual issues of development and scientific methodological support of national sports and folk games of the republic of Sakha (Yakutia): materials of the all-Russian scientific conference with international participation. Yakutsk. 2017, pp. 195-197.

[10] Lubysheva L.I. Sportization of physical education as a factor of socialization of the younger generation. International sports games "children of Asia" - a factor of promotion of ideas of Olympism and preparation of sports reserve: materials of the international scientific conference. Yakutsk. 2016, pp. 57-61.

[11] Nakhodkin V.V. The science of winning, or how to raise a winner: method. Recommendations. Yakutsk: publishing house. 2016, 80.

[12] Nikolaenko O.N. Strategy of personality self-control. Candidate's thesis. St. Petersburg. 2006, 200. 
[15] Sopov V.F. Mental states in strenuous professional activity. Moscow: academic project. 2005, 128 .

[16] Tadar-ool L.A. The role of national sports in the spiritual and moral education of children in the family and school. Topical issues of development and scientific methodological support of national sports and folk games of the republic of Sakha (Yakutia): materials of the allRussian scientific conference with international participation. Yakutsk. 2017, pp. 346-348. 